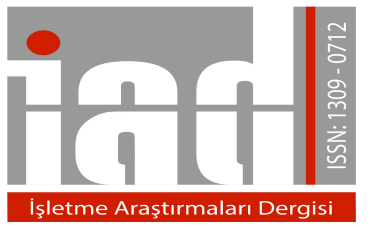

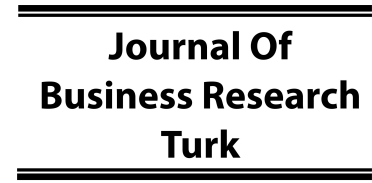

www.isarder.org

\title{
A Qualitative Study of Indonesian Telecommunication Company Service Representatives Role Conflict
}

\author{
Tony WIJAYA \\ Universitas Negeri Yogyakarta \\ Faculty of Economic \\ Indonesia \\ orcid.org/0000-0002-9666-9766 \\ Tony@uny.ac.id
}

\begin{abstract}
This research aimed to explore the role conflict experienced by the service representative in the telecommunication company. The type of this research is descriptive-qualitative research. The subject of research in this research is a front-linear employee (a service representative). In this study, data collection is done by using interviews. Data analysis in this study using descriptive qualitative research is trying to tell the problem solving that is now based on the data along with Focus Group Discussion. It was found that the company service representative has experienced conflict in the workplace, where trying to maintain emotion, hospitality and always smiling to the consumer in his job by not showing the negative mood that was experienced at that time. The unclear job description is also the cause of conflicts in employees. The work's load is borne by the employee is too large because as a service representative, an employee is required to be ready to face the consumer in a happy state or not. The main cause of conflicts within the individual is caused by internal factors that is the responsibility borne by the service representative. Negative influences that arise due to the conflict is to cause negative emotions and stress, reduce the communication necessary for coordination and cooperation among fellow service representative. Conflict within the individual affects the service.
\end{abstract}

Keywords: Role conflict, service representatives, service company

\section{Introduction}

Changes in the paradigm of service require changes in the management of organizational activities. The old view of service must be abandoned and replaced with new views. The main challenge faced by service managers is how companies are able to manage the customer satisfaction in the service area. Recent research clearly proves that there is a positive relationship between customer satisfaction and company profitability (Anderson et al, 1994). The characteristics and dynamics of interpersonal interactions between customers and service representative in the delivery of services have been a 
considerable focus of extant research in services marketing (Mäki \& Kokko, 2012). Research in recent time has focused on employee as organizations marketing-oriented and have responsible for triggering customer dissatisfaction, anger dan even range (Akkawanitcha et al., 2015). In theory, if company service representatives respond effectively levels are reduced and their propensity to engage in negative word of mouth communication is minimized (Garrett \& Meyers, 1996). The quality of a service organization's people is crucial for its market success and financial performance (Wirtz and Jerger, 2016).

One factor found to impact service encounters is service representative conflict. Conflict is inevitable in any social life domain and a common experience at the workplace (Beitler et al, 2016). The complex and conflicting organizational environment that service employees face raises significant questions about how different (and potentially conflicting) goals are communicated by management, and about how employees perceive, cope with and react to such conflicting demands (Luria et al, 2014).

The role of a service representative, among others, faces work demands or expectations that are often inappropriate (Kahn et al., 1964; Jackson \& Schuler, 1985). Inability to meet incompatible requests can generate role conflict. Service employee requested to serve different systems and consumers will tend to experience a role conflict (Boles \& Babin, 1996, Tansik, 1990). The service representative role conflict appears to be larger than that experienced by other workers and in different industries because literally service representatives are stretched across two environments. The service representatives not only have internal authority but also have external constituencies that often lead to expectations of different roles. Rafaeli (1989) found that consumers have a considerable time influence over a service representative, while the influence of management is legitimate or logical, but under control.

Service employees with frequent customer contact deal with elevated levels of social conflicts (Dormann and Zapf, 2004), and thus require distinct socioemotional competences, such as appropriate conflict management strategies, to successfully manage demanding customer interactions (Beitler et al, 2016). A company service representative role conflict has been linked to such negative outcomes as their own job dissatisfaction, turnover, burnout, and poor performance (Chung \& Schneider, 2002). The conflict that occurs within an organization can occur between individuals and between groups. Some opinions say that conflicts can't be avoided. Inter-group conflict can be a positive and negative force for the organization, so managers should not struggle to eliminate all conflicts. Organizations need only eliminate or minimize conflicts that have a disruptive impact on achieving organizational goals. The important issue is not the conflict itself but how to overcome and manage conflict, to be at a moderate level so as to improve the performance of motivating the organization to make changes or innovations. The organizational view of the conflict is transitioning, starting from a traditional view that considers all conflicts is negative. Conflict is seen as something that is harmful and should be avoided. Furthermore, in the view of human relations, conflict is a natural and inevitable event in every group and organization. Interactionist views assume that conflict is not only a positive force within a group but also absolutely necessary for a group to perform effectively.

The role of employees, especially front-stage employees in this service 
representative is very important in supporting the success of organizations, especially those engaged in the service sector. The employee is a service itself and serves as a communicator as well as a representative of a corporate image. Shostack (1977) argues that employees are often viewed as services themselves, the interaction between employees and consumers based on trust positively affects the company, because this relationship will create value for consumers which in turn will encourage loyalty (Guenzi and Pelloni, 2003). In the service business there is often an error in the interaction between the employee and the consumer, and because of the nature of the services of the inseparability (selling service) then the error in the interaction is inevitable (Mattila, 2002).

Front-line service employees may experience greater role conflict due to having a broader and more diverse role than other workers (Luria et al., 2014). A service representative connects the company (internal) to the environment (external) in which it operates. Working as a company service representative is the spearhead of a service company of any kind and anywhere because the nature of work as a service representative is to serve and strive to provide satisfaction to several parties at once. On the one hand service representative is required to provide the best service for customer satisfaction, and on the other hand, service representative must also work in accordance with what has been established by the company as a standard procedure of a company, in this case, service representative must be responsible to the supervisor. Both roles can lead to role conflict in service representative.

Role conflict is a situation that occurs when a worker experiences a discrepancy between what the worker thinks about consumer expectations and what the management will give as a reward. This role conflict is also a media relation or relationship between service orientation incompatibility with what workers have done (Chung and Schneider, 2002). Companies that want to be examined in this research are some companies engaged in Telecommunication services in Yogyakarta. Call centers have become a central element in companies' operations, as it is the main place of communication between the companies and their customers (Chicu et al, 2016). One major impact of organizational conflict on employee job performance clearly manifests in employees' poor commitment towards the job which in turn affect service quality and customer satisfaction (Chigozie, 2017).

The results of previous research, according to research conducted by Chung and Schneider (2002) the more service representative feels that service representatives are rewarded for conducive behaviors in meeting consumer expectations, the fewer role conflicts service representatives will experience. Role conflict is significantly associated with attitudinal outcomes (job satisfaction and turnover intent) as well as workers' absenteeism behavior. Positive role-related conflict with turnover intention and absenteeism behavior, and negatively with job satisfaction. Role conflict becomes the medium of a relationship between service mismatch and attitude outcome as well as other behavior.

This research will focus more on the workers in companies engaged in the world of service, commonly referred to as service representative. The service company itself is a company that offers and sells products in the form of services (intangible goods) to consumers through their service representative. The researcher chooses service representative as the subject of this research because in this case, service representative 
is a person who deals directly with the public (Bateson, 1989; Chung and Schneider, 2002). The paper is structured as follows: the first section of the paper includes an overview of the literature on role conflict and it's typing. Following this, the methodology are presented in the second section. The results of the empirical study are presented in the third section. The last section concludes and implications.

\section{Literature Review}

\section{Understanding Role Conflict}

According to Chung and Schneider (2002), the meaning of role conflict which, commonly referred to as role conflict often experienced by service workers, is a situation where a worker experiences a mismatch between what the worker thinks about consumer expectations and what will be given the management as a reward. Role conflict is a media mismatch between service orientation and what workers have done.

Kahn et al., (1964) stated that the nature of the role of service workers tends to deal with incompatible job demand or expectations. The inability to meet incompatible requests can lead to role conflict. Service representative requested to run the system within the company and serve consumers, will tend to experience role conflict (Boles and Babin, 1996). Added by Dubinsky and Mattson (1979), that role conflict is strongly related to the negative outcomes of firms and workers, including job dissatisfaction, turnover (Singh et al., 1994) and poor employee performance (Schuler, 1977). Ertel (1999) defines role conflict as the opposition that arises in the individual caused by differences in demands that exist within the individual with real behavior.

According to Pickering (2001) role conflict is an emotional disturbance that occurs within a person because it is required to complete a job or meet an expectation while experience, interests, goals, and values might not meet the demands so that this becomes a burden for him. Role conflict reflects the difference between what is wanted and done in fulfilling that desire. From the definition of conflict role above, it can be concluded that role conflict is a conflict arising from the mismatch of service orientation with what has been done workers (outcomes) for the company.

Greenberg (2000) classifies the causes of role conflict into two main groups: factors related to organizational structure and interpersonal relationships. Organizational conditions that tend to lead to role conflict are dependence on information, assistance, and coordination, competition in obtaining scarce resources in organizations such as a distribution of space, money, equipment, and personnel, as well as organizational ambiguity and policy. The interpersonal conditions that cause role conflict are mistakes in interpreting the causes behind a person's behavior (faulty attributions), errors in communicating with others or the tendency to assume that views with others or the tendency to assume that self-perception is the most objective and reflect reality naïve realism). There are three main conditions that spur the occurrence of role conflict in the organization that is the difference of situation, state of uncertain status, and the existence of organizational rules (Cook \& Phillip, 2001).

\section{a. Differences situation}

The situation that individuals expect is different from the situation that the individual faces raise the conflict within the individual. For example, an employee expects a particular position but occupies positions that are not according to his wishes. 


\section{b. The uncertain state of a status}

Each individual expects a status within him if the expected status has not been obtained clearly then will create a conflict between the desired status with the current status. For example, a child wants a certain career but is rejected by the family.

c. The existence of organizational rules

Rules are something that limits and encourages every individual action in behaving. If the rules imposed are not appropriate for the necessity of individual action will form a role conflict within the individual. For example, a highly educated person performs a work order for a lowly educated person.

\section{Type of Role Conflict}

In addition to these three conditions, time orientation, resource allocation, status differences, value differences, assumptions, and perceptions can also trigger role conflict. Role conflict arises when the regulated situations in which an actor is needed to meet simultaneously two or more roles present inconsistent, contradictory or even reciprocal expectations exclusively (Getzels \& Guba, 1952). Kahn et al (1964) conducted a national study of role conflict and ambiguity and their results define conflict as a simultaneous occurrence of two (or more) roles that fulfill one thing but will make other things difficult to fulfill. In this case, Kahn et al (1964) also identify four different types of role conflict:

a. Intrasender conflict. This type of conflict occurs when a role sender needs a recipient of a role to perform opposite or inconsistent roles. For example, a role sender may require a role recipient to do something that can not be done without breaking a rule, because the sender of the role is trying to enforce the rules.

b. Intersender conflict. The role recipient will experience conflict if the role behavior required by a role sender is different from the behavior required by the other sender of the role. A person who frequently experiences role conflict is the foreman, who receives instructions from the public foreman who may be inconsistent with the needs and expectations of the workers below.

c. Interrole conflict. This type of conflict occurs when an individual occupies two or more roles that have an inconsistent expectation. A company leader is expected, in that role to take part in social work to promote the company's image. This may be in conflict in his role as a father where he is expected to spend more time with his children to become an ideal parent.

d. Intrarole (Person-Role) Conflict. This type of conflict occurs when a worker is required to violate moral or ethical values. For example, role conflict occurs when a manager is required to enter pricing conspiracies that are inconsistent with the standards of his ethics.

The role of a service representative, among others, faces work demands or expectations that are often inappropriate (Kahn et al., 1964; Jackson \& Schuler, 1985). Inability to meet incompatible requests can generate role conflict. Service employee requested to serve different systems and consumers will tend to experience a role conflict (Boles \& Babin, 1996, Tansik, 1990). The service representative role conflict appears to 
be larger than that experienced by other workers and in different industries because literally service representatives are stretched across two environments. The service representatives not only have internal authority but also have external constituencies that often lead to expectations of different roles. Rafaeli (1989) found that consumers have a considerable time influence over a service representative, while the influence of management is legitimate or logical, but under control.

The results of previous research, according to research conducted by Chung and Schneider (2002) the more a service representative feels that have rewarded for conducive behaviors in meeting consumer expectations, the fewer role conflicts service representatives will experience. Role conflict is significantly associated with attitudinal outcomes (job satisfaction and turnover intent) as well as workers' absenteeism behavior. Positive role-related conflict with turnover intention and absenteeism behavior, and negatively with job satisfaction.

\section{Methodology}

This type of research is descriptive-qualitative research, which aims to explore the role conflict experienced by company service representatives in the work environment. The subject of research in this research is a front-linear employee (service representatives). Selection of front-linear employees (service representatives) is the assumption that a service representative is a front-office employee who performs two functions that serve the consumer and company. This can lead to role conflict in a service representative to fulfill its duties to consumers and companies. Subject worked as a service representative in the field of telecommunication services especially call center. Selection of subjects with consideration, employment as a service employee in the field of call centers tend to experience role conflict. Call centers have become a central element in companies' operations, as it is the main place of communication between the companies and their customers (Chicu et al, 2016). One of the reasons employee callover turnover is customer over the phone get unreasonable and irritating (Budhwar et al., 2009). In this study, data collection is done by using direct interviews. The study used 22 respondents with more than 5 years of service as a service representatives in a large telecommunication service company that has been grouped into 4 major geographic groups of respondents as well as having conflicted roles from initial search results. Interview guides are openly developed through conflicting variables, causes of conflicts, conflicts, and the impact of conflicts on services. Data analysis in this research uses descriptive qualitative accompanied by Two-Way Focus Group Discussion involving telecommunication service researcher, company sales representative and supervisor.

\section{Results}

From interviews, all respondents as service representatives have experienced conflict in the workplace, in the sense that service representatives should try to keep emotions, hospitality and always smiling to the consumer in his or her work even though not in accordance with his mood. Every individual is inseparable from the problems that exist outside the office, but the service representatives must be able to perform its role as a service representative in the office well in accordance with procedures established by the company.

The responsibility of a service representative was quite heavy because the service representatives have to maintain good relationships between companies and consumers. 
Consumers who come cultivated comfort so that service representatives are comfortable and have a positive value to the company. Consumers are given input or counseling about the benefits of the company's products to attract consumers and have a positive image of the company's products. Respondents in the study said that the service representatives had a conflict. Here's informant's phrase when asked if the service representatives ever had a conflict.

Ever. Especially if we're not in the mood, it must have happened. Our work as service representatives, so it must be suppressed. (Resp1)

Conflict is always there. I am always there an everyday conflict, but as a service representative that must serve so must work as a service employee well. (Resp 2)

There is little conflict. As a service representative in this company, career ladder is not very clear, has 3 years working as a contract employee. (Resp 3)

Conflict often. The conflict that often happens today, I face 2 things:

I am responsible for the company to keep an image of the products that the company sells.

I also have to keep the customer coming must complain about other products. I have to be a good relationship with company and customer. (Resp 4)

The interpersonal conditions that cause role conflict are mistakes in interpreting the causes behind a person's behavior, the error in communicating with others or the tendency to assume that the views of others or the tendency to assume that the views of oneself as something most objective and reflect reality with the rules made by the company which creates controversy. This was revealed by respondents 3 and 4 as follows:

The rules that companies make are sometimes contrary to our rules, sometimes when faced with problems, sometimes demanding our wisdom to do things against the company. (Resp 3)

I think for the action that I am supposed to do to the service representatives is set in the method of company procedure, I think the boundaries are clear. (Resp 4)

The unclear job description is also the cause of conflicts in employees. The work's load is borne by the employee is too large because as a service representative, an employee is required to be ready to face the consumer in a happy state or not. The main cause of conflicts in all respondents is caused by internal factors that is the responsibility borne by the service representative. This was revealed by respondents 1,2,3 and 4 group as follows:

From career paths, perhaps due to personal conflicts and job descriptions are less clear. (Resp 1)

Most of the internal factors. But since I decided as a service representative I have dared to bear the risk with what I do, as we handle customers who are not normal, according to our true but according to the wrong company. (Resp 2)

Sometimes conflicts that arise must be caused by internal factors. But as a good service representative should be able to suppress from internal factors. (Resp 3)

The conflict that often arises as a service representative does not arise from within me, arise when I face a customer who is very promising, especially when I am very disappointed with the product and threatened to enter the mass media it will threaten me as an individual working as a service employee. (Resp 4) 
Role conflict can be an obstacle as well as support for performance. The impact that occurs on all respondents who stated that the conflicts that occur just be a challenge for the performance of respondents. This was revealed by respondents 1,2 and 4 as follows:

Although I am not satisfied, I try to work discipline if there is a decline in performance, it is beyond my consciousness. (Resp 1)

I feel that when I get into conflict, I'm encouraged to be a challenge. (Resp 2)

Conflict becomes an input/development, not a scourge. But $I$ always make this as a benchmark. Currently experiencing conflict then I have to grow more than ever. (Resp 4)

Do not want it does affect. But so far it does not affect performance. Performance reduction still occurs. (Resp 1)

Sometimes. Suppose we are wrong, we might not be egoity let alone we work in companies that have gone public, we must follow the procedures that exist in this company. (Resp 2)

In the face of conflict, I rarely feel to be lazy/undisciplined work. A conflict that happens will encourage me to learn more. (Resp 4)

Conflict can increase morale even though it sometimes decreases morale. This was revealed by respondent 3 as follows:

Sometimes yes. Sometimes it becomes motivation/encouragement. (Resp 3)

I feel indiscipline. The existence of conflict makes us not eager to work so that it is against the rules of the company. (Resp 3)

Conflict can cause disappointment in the individual and decrease the concentration of work, and cause a slightly higher level of tension and more constructive. This increases the probability of a satisfactory conflict resolution for all interested parties. If the level of tension is so low, the parties are not motivated enough to do a conflict. Negative influences that arise due to the conflict is to cause negative emotions and stress, reduce the communication necessary for coordination and cooperation among fellow service representatives. This was revealed by respondents 1,3 and 4 as follows:

Yes. want not even though it does not want it to be influential in our work, but subconsciously we will keep the disappointment as we want to work well or not, the rewards will be the same and it will relax our morale. (Resp 1)

A little. Because conflict usually makes performance/concentration less. But so far there has never been a fatal mistake. (Resp 3)

I think there is very little conflict affecting my performance. But with sharing with fellow service representatives will reduce our guilt in facing conflict. (Resp 4)

Conflict within the individual affects the individual's work. This influence can degrade performance if the individual who felt the role conflict felt the conflict as workload This was revealed by respondent 1 as follows:

Yes. Do not want to do it, even if you do not want it to work in our work, but under consciousness, we will keep the disappointment as we want to work well or not appreciation will be the same and it will relax our morale. (Resp 1)

Inner conflicts also do not affect the performance of individuals who respond to conflict as a work challenge. This was disclosed by respondents $2,3,4$ as follows:

No...(Resp 2 \& $\operatorname{Resp} 3)$ 


\section{No...The conflict did not degrade morale. (Resp 4)}

Service representatives seek to resolve the conflicts that occur within each of them. In solving conflicts, service representatives are usually assisted by other parties in the form of co-workers, family or others. Conflicts are solved through sharing or discussion together. This is expressed by respondents 2,3 and 4 as follows:

If there is a problem, I consult with the person who I think is appropriate/agree with me. Usually consulting job with a girlfriend. If consulting with co-workers then the problem will be difficult to solve because they are subjective, not objective. (Resp 2)

Even if you can not solve yourself, at least with a colleague/supervisor/coordinator. (Resp 3)

Certain. I often consult fellow service representatives/team leader/supervisor to be invited to share. (Resp 4)

Service representatives experience conflict problems caused by demands in prioritizing the interests of consumers and companies. The company expects an increase in the number of consumers even though the product offered is not quality while as a waiter for the consumer, the consumer expects the desired product quality. The expected situation service representatives are different from the situation faced, then it will cause conflict within the individual. The specific conflicts are caused by the responsibility of maintaining the company's product image and complaints from consumers. In addition, the causes of conflict are also caused by pressure from superiors, less solid work team, working atmosphere and professionalism work. Most service representatives are contract employees. The service representatives do not have a time limit on the contract, but as an individual requires a permanent job as a guarantee of life in the future.

\section{Discussion}

Conflicts that occur in service representatives related to several things: the responsibility to maintain the image of the company's products and complaints from consumers. Service representatives have a job that is different from other jobs, the service representatives run two major roles in a company. First, the service representatives work with consumers as co-producers (Lovelock, 1984; Chung and Schneider, 2002). The second role, as a place where consumers lean, in the sense that service representatives behavior is met that is a representation of the service company itself (Berry, 1995). Service representatives are not only in a position to influence but also required to be able to collect information about what experienced consumers, especially how the company can meet their needs.

It can cause role conflict in service representatives caused by unclear job description, internal factors in the form of customer complaints, disappointed consumers, low service representatives education, and psychological side in the form of psychological problems arising in service representatives. According to Ertel (1999), the cause of role conflict in the service employee is a factor that relates to the role of works and interpersonal relationships between service employee responsibilities to the company and works with consumers. Conditions that tend to lead to role conflict are dependence on information, assistance and coordination, accountability and organizational policy and confront complaints from consumers.

The impact of service representatives role conflict leads to work pressures that reduce the performance of working groups and service representatives to feel the discomfort in the work environment caused by a less conducive working atmosphere. 
This will decrease individual performance. Conflicting service representatives will experience undisciplined work so that performance degradation may result. This raises the intention to quit the job. According to Ertel (1999), the impact of role conflict also raises a number of things namely the work pressure thus reducing the performance of working groups and individuals to feel the discomfort in the work environment caused by a less conducive working atmosphere. This will decrease individual performance. At the needs level, role conflict may arise only in priority setting if the engagement of the government is restricted. The emphasis and failure of need fulfillment lead to the distortion of attitudes and behaviors that are the conditions of the conflict creator. If needs are satisfied, then conflict can be avoided. Role conflict is a conflict that arises in the individual caused by differences in demands that exist within the individual with real behavior. Role conflicts tend to be experienced by service representatives requested to run the system within the company and serve the consumer, because the task of service representatives is to serve the consumer with various problems and complaints.

Work as a service representative needed people who are friendly, patient, and have extensive knowledge. In addition, the company also sets the criteria for physical terms such as ideal posture, height, and a certain age. So that is often the cause of conflict because people are often no longer needed or required to resign because of age that is not in accordance with company criteria. While humans hope that the longer a service representatives work, the service representatives expect to have a steady job. But as a service representative, it is not possible to be fulfilled. Role conflict will have an impact on everyday life ie barriers in everyday life. At a mild stage, role conflict will cause a headache and back pain, stress and despair. The impact of role conflict for the organization includes decreased productivity, declining beliefs, the formation of hostile groups, and moral issues arise. Service representatives experience the conflict then will try to solve a conflict by sharing with a personal friend, supervisor or supervisor and sharing with team leader or co-worker.

Conflicting service representatives will then attempt to resolve the conflict by sharing with personal friends, sharing supervisors or supervisors, and sharing with team leaders or co-workers. Efforts to resolve conflicts within the individual require patience that is a required trait that has been inherent in a service representative. Service representatives have to be patient with consumer complaints by providing the products correctly and in accordance with company procedures. The interpersonal conditions that cause role conflict are misinterpretations of the causes behind a person's behavior (faulty attributions), errors in communicating with others or the tendency to assume that views with others or the tendency to regard self-views as something most objective.

\section{Conclusions}

Based on the analysis, all respondents as a service representative have experienced conflict in the workplace, in the sense that the service representative should try to keep emotion, hospitality and always smiling to the consumer in his work by not showing the bad mood that she was experiencing at that time. Most service representatives are contract employees. The service representatives do not have a time limit on the contract, but as an individual requires a permanent job as a guarantee of life in the future. This result support the point Cook \& Phillip (2001) made; that status uncertainty will create a conflict between the desired status and the current status. The unclear job description is also the cause of conflicts in employees. The work's load is borne by the employee is too large because as a service representative, an employee is required to be ready to face the 
consumer in a happy state or not. The main cause of conflicts within the individual is caused by internal factors that is the responsibility borne by the service representatives. Conflict is a problem for the decline in morale, individuals who feel the conflict feel the decrease in morale, but there are those who feel not feel the effects of conflict because service representatives feel challenged to learn and work discipline. Negative influences that arise due to the conflict is to cause negative emotions and stress, reduce the communication necessary for coordination and cooperation among fellow service representatives. These results are consistent with Chung and Schneider (2002) that role conflict negatively impacts employees such as job dissatisfaction.

Conflict within the individual affects the individual's work. Such influence may decrease service if individuals who perceive role conflict perceive conflict as workload but role conflict does not affect the service of individuals who respond to conflict as a work challenge. Thus can be identified if service representatives experience conflict then will try to resolve conflict with sharing with a personal friend, sharing supervisor or supervisor and sharing with team leader or coworker

Theoretically, the results of this study are expected to contribute empirical evidence to the science of service company, especially about role conflict in service representatives. In addition, the results of this study can also contribute to the company to pay attention to the role conflict in the service representatives by clarifying the job description, recruiting permanent employees, as well as improve the relationship between personal service representatives resulting in the sharing of a build. Work as a service representative needed people who are friendly, patient, and have extensive knowledge. In addition, the company also sets these criteria in the recruitment process.

\section{References}

Anderson, E.W., Claes, F., Donald, R.L. (1994). Customer satisfaction, market share, and profitability: Finding from Sweden, Journal of Marketing, 58, 53-66.

Akkawanitcha, C., Patterson, P., Buranapin, S., Kantabutra, S. (2015). Frontline employees' cognitive appraisals and well-being in the face of customer aggression in an Eastern, collectivist culture, Journal of Services Marketing, 29, 268 - 279

Bateson, J.E.G. (1989). Managing service marketing: Text and Readings. Orlando, Fla: Dryden Press.

Berry, L.L.(1995). On great services. New York, NY: Free Press.

Beitler, L, A., Sabine, M., Sheena. J., Zapf., D. (2016). Conflict management and age in service professions. International Journal of Conflict Management, 27, 302-330.

Boles, J.S., Babin, B.J. (1996). On the front-lines: Stress, conflict, and the customer services provider. Journal of Business Research, 37, 41-50.

Budhwar, P.S., Varma, A., Malhotra, N., Mukherjee, A. (2009). Insights into the Indian call centre indsutry: can internal marketing help tackle high employee turnover? Journal of Services Marketing, 23, 351-362.

Chicu, D., Ryan, G., Aparicio, M, V. (2016). Determinants of customer satisfaction in call centers. European Accounting and Management Review, 2, 20-41.

Chigozie, D, E. (2017). Impact of organizational conflict on employee job performance in selected hotels (in Lagos Nigeria), TURIZAM, 21, 45-64.

Chung, B, G., Schneider., B. (2002). Serving multiple masters: Role conflict experienced by service employees. Journal of Services Marketing, 16, 70-87. 
Cook., C, W., Phillip., L.H. (2001). Management and organizational behavior, $3^{\text {rd }}$ ed, NY: Mc-Graw Hill

Dormann, C., Zapf., D. (2004). Customer-related social stressors and burnout. Journal of Occupational Health Psychology, 9, 61-82

Dubinski, A.J., Mattson., B.E. (1979). Consequences of role conflict and ambiguity experienced by retail salespeople. Journal of Retailing, 55, 70-86.

Ertel, D. (1999). How to design a conflict. Management procedure that fits your dispute, Sloan Management Review.

Garrett, D.E., Meyers, R. A. (1996). Verbal communication between complaining consumers and company service representatives. The Journal of Consumer Affairs, 30, 444-473.

Getzels, J.W., Guba, E.G. (1952). Role, role conflict and effectiveness: An empirical study. American Sociological Review, 19, 164-175.

Greenberg, J. (2000). Behavior in organizations. New Jersey: Prentice Hall Inc.

Guenzi, P., Pelloni., O. (2003). Interpersonal relationship and customer loyalty: A comprehensive model and empirical investigation", Paper, Instituto di Economia e Gestione delle Impresse, Italy, Millano: Universita Commerciale Luigi Bocconi.

Kahn, R.L., Wolfe., Q., Snoek., Rosenthal. (1964). Occupational stress: Studies in role conflict and ambiguity. New York: Wiley

Jackson, S. E., Schuler, R. S. (1985). A meta-analysis and conceptual critique of research on role ambiguity and role conflict in work settings. Organizational Behavior \& Human Decision Processes, 36, 16-78

Lovelock, C.H. (1984). Services marketing. Engelwood, Cliffs, NJ: Prentice-Hall.

Luria, G., Yagil, D., Iddo, G. (2014). Quality and productivity: Role conflict in the service context, The Service Industries Journal, 34, 955-973

Mäki, M., Kokko, T. (2012). Customer participation in retail-focus on automated services. Journal of Business and Retail Management Research, 7, 94-105.

Mattila, A. S., Enz, C. A. (2002). The role of emotions in service encounters. Journal of Service Research, 4, 268-277

Pickering., S. (2001). Common sense and original deviancy: News discourses and asylum seekers in Australia. Journal of Refugee Studies, 14, 169-86.

Rafaeli, A. (1989). When cashiers meet customers: An analysis of the role of supermarket cashiers. Academy of Management Journal, 22: 270-81.

Robbins, S.P. (2001). Organization behavior: Concepts, controversies, applications, $9^{\text {th }}$ ed, New Jersey: Prentice Hall Inc.

Schuler, R. S. (1977). The effect of role perceptions on employee satisfaction and performance moderated by employee ability. Organizational Behavior and Human Performance, 13, 98-107

Shostack, G. L. (1977). Breaking free from product marketing. Journal of Marketing, $41,73-80$.

Singh, J., Goolsby, J.R., Road, J.K. (1994). Behavioral and psychological consequences of boundary spanning: Burnout of customer services representatives, Journal of Marketing Resources, 31, 58-69.

Tansik, D.A. (1990). Managing human resource issues for high contact personnel. In: Bowen, D.E., Chase, R.B., Cummings, T.G. (Eds.), Service Management Effectiveness. Jossey-Bass, San Francisco, 152-176.

Wirtz, J., Jerger, C. (2016). Managing service employees: literature review, expert opinions, and research directions, The Service Industries Journal, 36, 757-788. 